This item was submitted to Loughborough's Research Repository by the author.

Items in Figshare are protected by copyright, with all rights reserved, unless otherwise indicated.

\title{
Experimental analysis of super-knock occurrence based on a spark ignition engine with high compression ratio
}

PLEASE CITE THE PUBLISHED VERSION

https://doi.org/10.1016/j.energy.2018.09.166

PUBLISHER

(C) Elsevier

VERSION

AM (Accepted Manuscript)

PUBLISHER STATEMENT

This paper was accepted for publication in the journal Energy and the definitive published version is available at https://doi.org/10.1016/j.energy.2018.09.166.

\section{LICENCE}

CC BY-NC-ND 4.0

\section{REPOSITORY RECORD}

Zhou, Lei, Rui Kang, Haiqiao Wei, Dengquan Feng, Jianxiong Hua, Jiaying Pan, and Rui Chen. 2018.

"Experimental Analysis of Super-knock Occurrence Based on a Spark Ignition Engine with High Compression Ratio". figshare. https://hdl.handle.net/2134/35203. 


\section{Experimental analysis of super-knock occurrence based on a spark ignition engine with high compression ratio}

Lei Zhou\#, Rui Kang\#, Haiqiao Wei*, Dengquan Feng, Jianxiong Hua, Jiaying Pan, Rui Chen

State Key Laboratory of Engines, Tianjin University, Tianjin 300072, China

*Corresponding author: Haiqiao Wei

Email:whq@tju.edu.cn

Tel.: +86-22-27402609

Address: 92 Weijin Road, Nankai District, Tianjin, P. R. China

\#These authors contributed equally to this work and should be considered co-first authors.

A video named "Detailed pressure evolutions in 200 successive cycles" is available in Supplemental Material. 


\section{Abstract:}

The super-knock phenomenon is a major obstacle for further improving the power density in SI engines. The objective of this paper is to experimentally investigating the mechanism involved in the occurrence of super-knock. In this work, a high compression ratio $(\mathrm{CR}=13)$ coupled with advanced spark timings were employed to achieving intense or critical thermal-dynamic conditions to easily inducing the super-knock. The results show that super-knock can originate from spark ignition, which is different from previous results regarding pre-ignition. Changing the spark timing super-knock can be induced with very high pressure oscillation at the present high compression ratio. The high compression ratio could generate sufficiently high thermal-dynamic conditions to inducing the abnormal combustion. In this research, four combustion phenomena were observed. The present work indicates that there is a nonlinear relationship between knock intensity and knocking onset in terms of pressure profiles at different cycles. The super-knock or knock phenomena were dominantly induced by spark ignition, which were controlled by the pre-ignition after several cycles. Finally, the analysis of the mechanism of super-knock with severe pressure oscillation was employed based on the thermal explosion theory and cavity resonances. There are two possible auto-ignition combustion modes that can induce the intense pressure oscillation.

Keywords: super-knock; pre-ignition; high compression ratio; pressure oscillation; combustion modes

\section{Introduction}

Strict legislations on $\mathrm{CO} 2$ emissions and the global energy crisis have resulted in intense efforts to improve the thermal efficiency and reduce fuel consumption in the automotive field. Therefore, at present, the development of direct injection (DI) spark ignition (SI) engines focus on downsizing or high boost to improving power density, fuel consumption, lower $\mathrm{CO}_{2}$ emissions, and thermal efficiency[1-3]. However, with the increase of engine compression rations, abnormal combustion of knock is likely to occur. The phenomenon of knock seriously limits the improvement of thermal efficiency of SI engines.

At present, many experimental and numerical investigations have been conducted to investigate the fundamental mechanism of knock by various devices such as optical engine[4], rapid compression machine[5], optical constant volume bomb[6]. Meanwhile, various methods was adopted to suppress the knock occurrence 
such as Miller cycle[7], exhaust gas recirculation (EGR)[8] and alternative fuels[9]. For example, Marseglia et al.[10] made full use of the combination of optical engines and CFD simulation methods and further investigated the link between injection strategy and knock onset in an optical GDI engine through a synergic experimental and numerical methodology. It provides novel insights and methods for the investigation of knock. In summary, numbers of valuable research works have been conducted, a series of effective methods have been developed to suppressing knock in SI engines[11].

However, high loads in a high boost engine could also induce severe thermodynamic conditions in the cylinder, which could $[1,12]$ cause extremely high-intensity knock events. These knock events are generally described as “super-knock” or “mega-knock” [1, 12-14]. Super-knock can lead to very high peak pressure ( 30 MPa) and pressure oscillation ( 10 MPa), which can significantly damage the cylinder or piston. Therefore, the super-knock phenomenon becomes a major obstacle in improving engine performance[1]. However, the underlying mechanism responsible for the occurrence of super-knock is still not completely clear.

Significant advances have been made over the past years in understanding the mechanism of super-knock occurrences by different simulations and experiments $[1,2,12,13,15-20]$. The super-knock phenomenon is significantly different from conventional knock. Conventional knock is due to end-gas auto ignition induced by the spark-triggered flame propagation. As a general point, super-knock events could appear occasionally with little direct relationship to engine control parameters such as ignition timing, air-fuel ratio, and coolant temperature. Super knock maybe originate from the pre-ignition [1, 12]. Pre-ignition means that a stable flame kernel is established by a hot spot before spark timing [21]. The possible source of the hot spot can include one of the following: lubricant oil droplets, fuel, particles, and surface ignition [22]. In addition, Wang et al.[23] proposed that the mechanism of super-knock is constituted by hotspot-induced deflagration to detonation followed by high-pressure oscillation (DDP). In recently comprehensive reviews by Wang et al.[1, 13] and Kalghatgi[1, 13], the relationship between super-knock and pre-ignition was defined. Their research showed that pre-ignition may lead to super-knock, heavy-knock and normal combustion (non-knock). However, the occurrence of super-knock requires the pre-ignition to occur before normal spark timing. Similarly, Kalghatgi and Bradley[2] presented observations that super-knock with a high pressure fluctuation is created by the occasional pre-ignition, which may depends on the critical conditions of auto-ignition within the cylinder. The same thinking is well supported by the works of Rudloff et al.[21]. Robert et al.[16] presented the calculated 
peninsula diagram in a large eddy simulation study on super-knock prediction. Their research found that the detonation occurrence is likely consistent with the evolution of knock intensity with advancing spark timing.

Based on the previous studies, two key conclusions can be found: that the super-knock phenomenon may be caused by pre-ignition, and that super-knock is an occasional occurrence. Early pre-ignition allows engine to compress the mixture to a higher temperature and pressure, which may lead to a lower auto-ignition delay time, and the super-knock occurs at a certain condition [2]. However, in theory, the super-knock should only be dependent on the relevant thermodynamic conditions of the mixture in the unburned region, such as temperature, pressure, concentrations and their gradients. Therefore, the thermodynamic conditions should be the only key point, and the pre-ignition is not the unique condition leading to super-knock. In this respect, above two conclusions should be not absolute, and the real mechanism has not been completely understood yet. knock occurrence. In this work, a high compression ratio $(\mathrm{CR}=13)$ was employed to inducing the super-knock by advancing the spark timing to achieving critical thermo-dynamic conditions. The characteristics of superknock phenomenon were analyzed, including the onset of occurrence, pressure oscillation, and frequency. Different from previous studies and known knowledge [1,13], the present work gives the distinct conclusion with respect with the cause of super-knock occurrence. In addition, the relationship between knock intensity and knock onset was investigated. Simultaneously, fundamental analyses were conducted based on fundamental experiments and cavity resonances. In order to further understanding the mechanism of super-knock, to the best of our knowledge, two more reasons for the super-knock caused by pre-ignition and spark ignition were proposed in this work. Meanwhile, the thermal explosion theory and cavity resonances were used to clarify the mechanism of this super knock. The present work provides novel insights into the mechanism of super-knock occurrence. given in Section 4. 


\section{Experimental setup and methodology}

\section{$81 \quad 2.1$ Engine and instruments}

Experiments were conducted with a single-cylinder, four-stroke, water-cooled, direct-injection spark

83 ignition engine. The engine combustion chamber contains of a protruded piston and a pent-roof cylinder head

84 in order to achieving high compression ratio of $\mathrm{CR}=13$. Engine's geometrical specifications and some detailed

85 parameters are presented in Table 1. A Siemens VDO piezoelectric pintle injector was selected as the direct fuel

86 injector. The injector is mounted on the intake port intake side. In order to forming a homogeneous mixture as

87 much as possible and reduce the impact of stratified mixture, DI injection pressure was 20 MPa with SOI of

$88360^{\circ} \mathrm{CA}$ bTDC in the beginning of intake process. Engine spark timing was controlled by an open ECU from

89 MoTeC. DI injection timing, DI pressure and DI duration were adjusted by using developed in-house

90 programming in the LabVIEW software. The overall air-fuel equivalence ratio was determined by a wideband

91 lambda sensor with uncertainty of $\pm 0.8 \%$ and response time of $0.15 \mathrm{~s}$.

Table 1 Engine Specifications

\begin{tabular}{c|c}
\hline Engine type & Single cylinder, 4-stroke \\
\hline Bore $\times$ Stroke & $80 \times 100 \mathrm{~mm}$ \\
\hline Sweep volume & $0.5 \mathrm{~L}$ \\
\hline Compression ratio & $13: 1$ \\
\hline Valve mechanism & $\mathrm{VVT}$ \\
\hline DI pressure & $20 \mathrm{MPa}$ \\
\hline SOI timing & $360^{\circ}$ CA bTDC \\
\hline Fuel & RON92\#gasoline
\end{tabular}




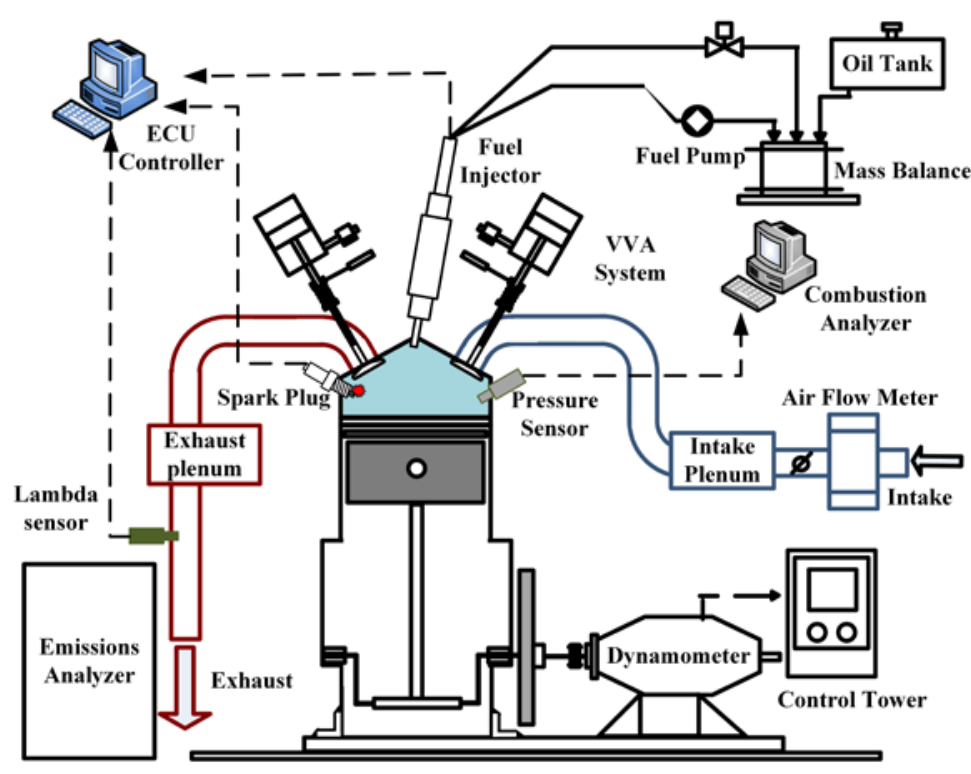

Fig. 1. Schematic view of engine and instrumentation setup.

The engine was coupled to a direct current dynamometer to maintain a constant speed of $1500 \mathrm{r} / \mathrm{min}$ with an accuracy of $\pm 1 \mathrm{r} / \mathrm{min}$. Engine load was determined by a ZEMIC H3-C3-200kg-3B load cell with an uncertainty of $\pm 0.5 \%$. A piezo-electric pressure transducer (Kistler $6118 \mathrm{~B}$ ) was flush mounted on the engine head to acquire in-cylinder pressure date. The natural frequency is approximately $90 \mathrm{kHz}$. The pressure transducer was placed in the cylinder head near exhaust valve, who arranged on the opposite side of the injector. Pressure sampling was triggered using a digital encoder coupled to the crankshaft with resolution of 0.1 CAD. The signals were sent to a Kistler 5018 charge amplifier and acquired by a National Instruments PC-6123 data acquisition card. Coolant and oil temperatures were measured using a PT-100 platinum resistance sensor and controlled by a SIEMENS proportional-integral-differential (PID) controller with uncertainty of $\pm 3{ }^{\circ} \mathrm{C}$. The RON 92 gasoline was supplied by Shell in China. The schematic view of general engine setup is presented in Fig. 1.

\subsection{Experimental procedure}

Engine tests were performed after warming the coolant and oil temperatures to $85 \pm 3{ }^{\circ} \mathrm{C}$ and $95 \pm 3{ }^{\circ} \mathrm{C}$, respectively. Meanwhile, a 100\% engine load with wide open throttle (WOT) was kept constant during the test.

110 A wideband lambda sensor was used to measuring the overall air-fuel mixture lambda ratio. During the experimental tests, the DI duration was adjusted in real time to maintain the overall air-fuel mixture lambda ratio at $1 \pm 0.01$. The air temperature was maintained at $25 \pm 3{ }^{\circ} \mathrm{C}$ by an air conditioning system to avoiding intake 
113 air temperature fluctuations, and the intake air pressure was maintained at 1.0 bar. During the test, spark timing

114 was swept from 0 to $8^{\circ} \mathrm{CA}$ bTDC with $1^{\circ} \mathrm{CA}$ intervals to achieving different levels of knocking combustion.

115 The experiments were operated under high load conditions with a high compression ratio engine since knocking

116 combustion is highly probable with advanced spark timings. Every test condition was repeated three times to

117 ensuring improved accuracy.

\section{$118 \quad 2.3$ Knock and super-knock criteria}

119 High frequency pressure oscillations exist in combustion chamber when knocking combustion happens.

120 Many researches pointed out that knock frequencies were observed in the range of 4-20 kHz [24, 25]. But the 121 super-knock generally causes high-frequency oscillations. Therefore, a high-pass filter with a cutoff $4 \mathrm{kHz}$ is 122 used to extracting the pressure oscillations from the original in-cylinder pressure signals. In order to analyzing 123 the effect of different super-knock modes on knocking combustion characteristics, knock intensity was 124 compared in this paper. Knock intensity (KI) was defined as the absolute peak value of high-pass filtered 125 pressure trace. KI threshold is set as 0.1 MPa since audible knock can be clearly noticed when KI exceeded this 126 value [26, 27]. In this study, the criterion for KI is $0.1 \mathrm{MPa}$ and a cycle is considered a knock cycle when KI is 127 greater than $0.1 \mathrm{MPa}[28]$.

128 Based on the current criteria, cycles with the maximum pressure higher than $150 \%$ of the normal combustion 129 are considered as super-knock. In this paper, cycles with the maximum cylinder pressure higher than $10 \mathrm{MPa}$ 130 and oscillation pressure higher than 2.0 MPa are considered as super-knock cycles according to the work [12]. 131 The criterion is high enough to distinguishing the knock and super knock cycles. 


\subsection{Qualitative analysis on super-knock inducements}
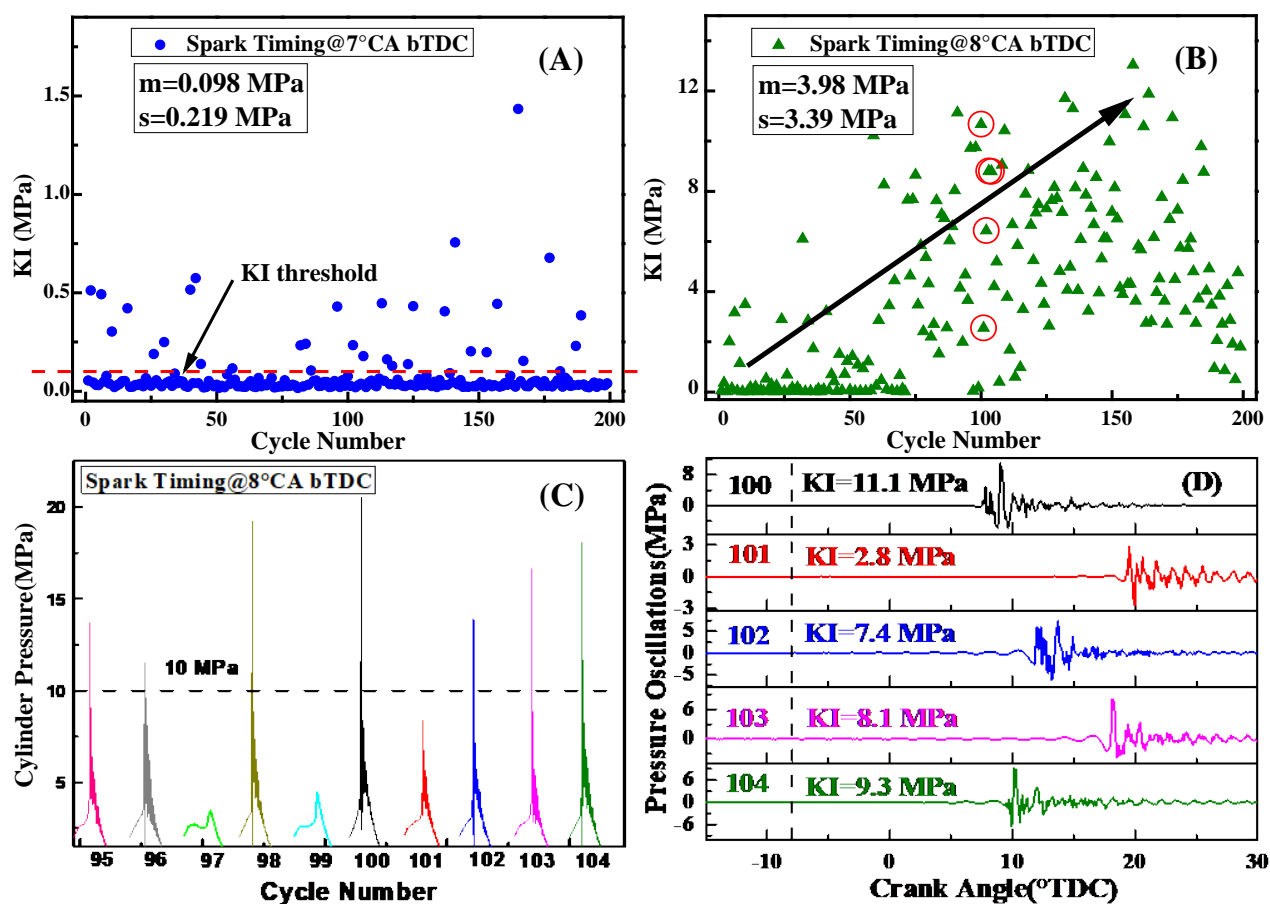

Fig. 2. Statistics analysis: characteristic of super-knock caused by spark ignition and pre-ignition.

Figures 2(A) and 2(B) show the KI of successive 200 cycles at a spark timing of $7^{\circ} \mathrm{CA}$ bTDC and $8^{\circ} \mathrm{CA}$

bTDC, respectively. It can be seen that, as the spark timing advances, the mean value of KIs rapidly increased.

Super-knock can damage the engine due to the extremely high peak pressure and pressure oscillation. Hence,

the spark timing is maintained at the normal combustion spark timing ( $3^{\circ} \mathrm{CA}$ bTDC) during engine normal operation, in which knock cannot be found. In order to studying the effect of spark timing on knock occurrence, the spark timing was adjusted from $3^{\circ} \mathrm{CA}$ bTDC to the test of spark timing, and immediately records the cylinder-pressure data. After the recording is completed, it will be adjusted to normal combustion spark timing ( $3^{\circ}$ CA bTDC) immediately. Note that in Fig. 2, the mean value $\mu$ and standard deviation $\sigma$ are introduced to quantify the distribution of KI. A low $\sigma$ value indicates that the sample points tend to be close to the mean value of KIs.

The KI showed a significant increase with advancing the spark timing in the high compression ratio engine. increased from 0.098 MPa to 3.98 MPa. It can also be seen that in the engine working process, all KIs 
significantly increased at a spark timing of $8^{\circ} \mathrm{CA}$ bTDC. The advancing spark timing allows the engine to 150 compress the mixture to a higher temperature and pressure, which can improve the possibility of end-gas auto151 ignition and thus, super-knock occurrences. After several initial cycles, the entire combustion chamber 152 temperature, including wall temperature, was increased, which also plays a key role in promoting the occurrence of super-knock. Figure 2(C) shows the pressure profiles at ten successive cycles with a spark timing of $8^{\circ} \mathrm{CA}$ 154 bTDC. It should be noted that there were 7 peaks of in-cylinder pressures exceeding $10 \mathrm{MPa}$ in 10 successive 155 cycles.

156 Many researchers regard super-knock caused by pre-ignition as being characteristic of engine self-cleaning 157 and randomness [29]. In previous study, pressure traces of 20000 engine cycles were recorded, which were post 158 processed to capture super-knock cycles[30]. In order to avoiding engine damage, the data of 200 cycles were recorded at a spark timing of $7^{\circ} \mathrm{CA}$ bTDC in this study. At the spark timing of $7^{\circ} \mathrm{CA}$ bTDC, the super-knock was not observed. However, when advancing the at a spark timing to $8^{\circ} \mathrm{CA}$ bTDC, the super-knock occurrence demonstrated a completely different phenomenon and presented successive characteristics observed from the data of 200 cycles. To further understanding the differences between the types of super-knock, oscillation pressure and knock onset need to be analyzed. The different pressure oscillations during five successive cycles are shown in Fig. 2(D). It can be seen that the maximum amplitude of pressure oscillation exceeded 2.0 MPa. In particular, pressure oscillations at a cycle of 103 with a very later onset of super-knock were observed. Therefore, according to the criteria of super-knock in section 2.3, the super-knock in this paper meets this evaluation index. But based on the super-knock caused by pre-ignition characteristic of self-cleaning and randomness in previous researchers [1, 20, 29], the successive occurrence of super-knock was different from the super-knock induced by the pre-ignition. 


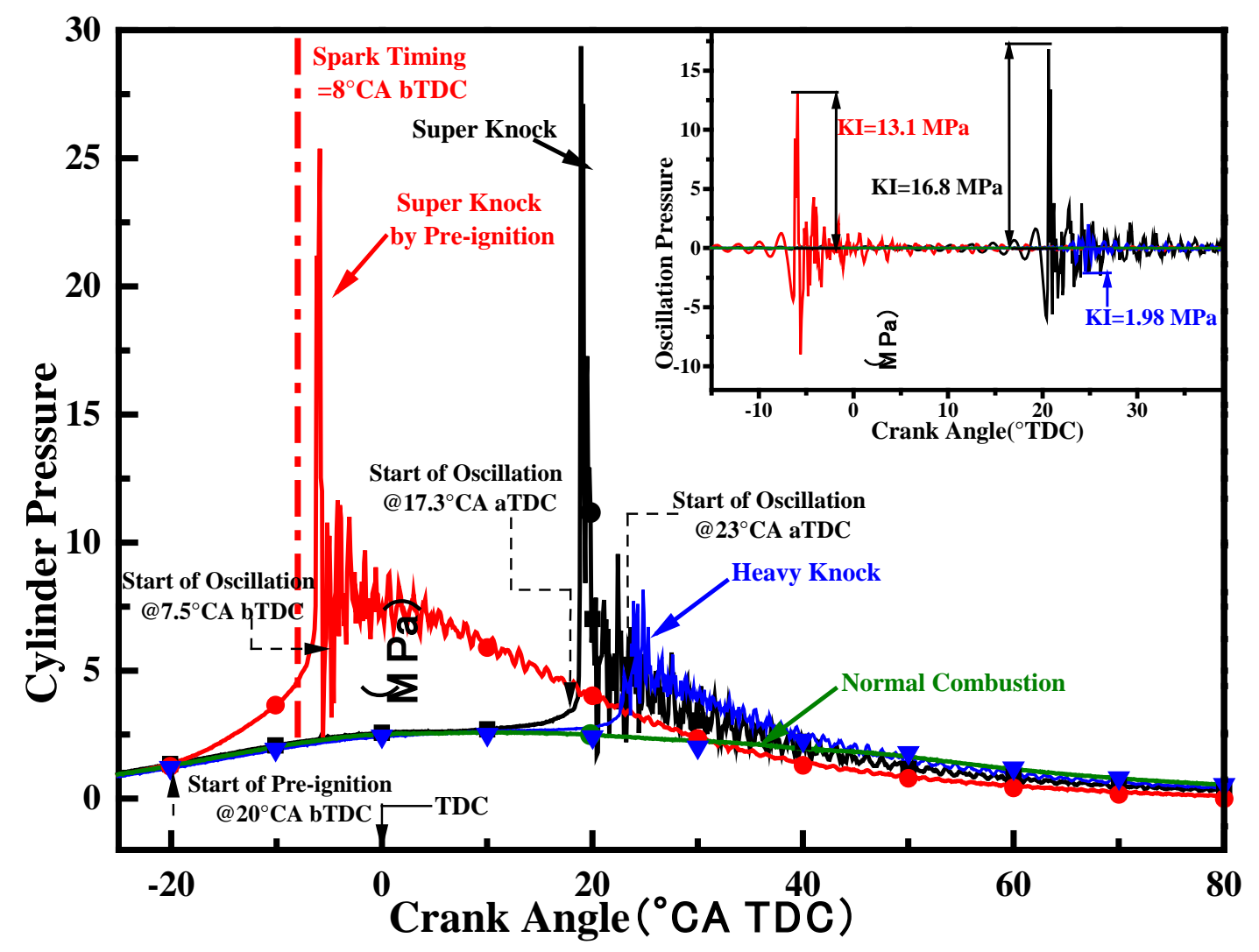

Fig. 3. Pressure profiles and pressure oscillation for typical knock combustion at spark timing of $8^{\circ} \mathrm{CA}$ bTDC.

Figure 3 compares the in-cylinder pressure profiles and pressure oscillations（High-pass filter, $\mathrm{F}>4 \mathrm{kHz}$ )

of normal combustion, heavy-knock, spark-ignition induced super-knock, and pre-ignition induced super-knock with the identical spark-ignition timing of $8^{\circ}$ CA bTDC. Under the same operating conditions, normal combustion, conventional knock, super-knock, spark ignition induced super-knock, and pre-ignition induced super-knock appeared in different cycles. The green and blue lines show typical cycles of normal combustion and heavy-knock, respectively. Due to knock-limit, the spark timing retarded and the corresponding peak cylinder pressure was 2.98 MPa for normal combustion. In Fig. 3, the red lines show a typical cycle of preignition induced super-knock. The in-cylinder pressure profile significantly deviates from the normal combustion (green lines) cycle at $20^{\circ} \mathrm{CA}$ bTDC, which indicates a pre-ignition before normal spark timing of $8^{\circ}$ CA bTDC. Due to the pre-ignition flame propagation and piston motion, the end-gas was compressed to a state of high temperature and high pressure in a short time; subsequently, spontaneous ignition occurred. The chemical reaction and rapid heat releasing occurs in a short time and within a small space. The heat released promotes pressure wave propagation in the combustion chamber, resulting in a strong pressure oscillation with 
186 an oscillation amplitude of $13.1 \mathrm{MPa}$ at approximately $7.5^{\circ} \mathrm{CA}$ bTDC based on KI. The red line is a typical 187 cycle for super-knock caused by pre-ignition, which is consistent with previous works with respect to that the 188 super-knock phenomenon is only caused by pre-ignition.

189 In Fig. 3, the black line indicates a typical cycle of super-knock induced by spark ignition. For several 190 crank angles (a certain time) after spark ignition, the pressure profile of spark ignition induced super-knock 191 keeps a consistent trend with that of normal combustion. Compressed by the flame propagation, end-gas reached 192 a state of high temperature and high pressure rapidly. Spontaneous ignition occurred at $10^{\circ} \mathrm{CA}$ aTDC, and 193 subsequently, the pressure profile deviated from the normal combustion. A severe pressure oscillation with an 194 amplitude of $16.8 \mathrm{MPa}$ occurred at $17.3^{\circ} \mathrm{CA}$ aTDC based on KI, which meets the criteria of super-knock. Note 195 that for the high compression ratio, both pressure and temperature achieve the threshold to promote auto-ignition. 196 Therefore, the different combustion modes are sensitive to the operating conditions, such as wall temperature, 197 cool water, cycle-to-cycle variation, and so on. The present result clarifies that the super-knock could be induced 198 by spark ignition not only pre-ignition. The relevantly underlying explanations will be discussed later. In 199 summary, super-knock, whether caused by pre-ignition or spark ignition, will lead to high pressure and strong 200 pressure oscillation within the cylinder. The only difference between them is the onset of ignition. 


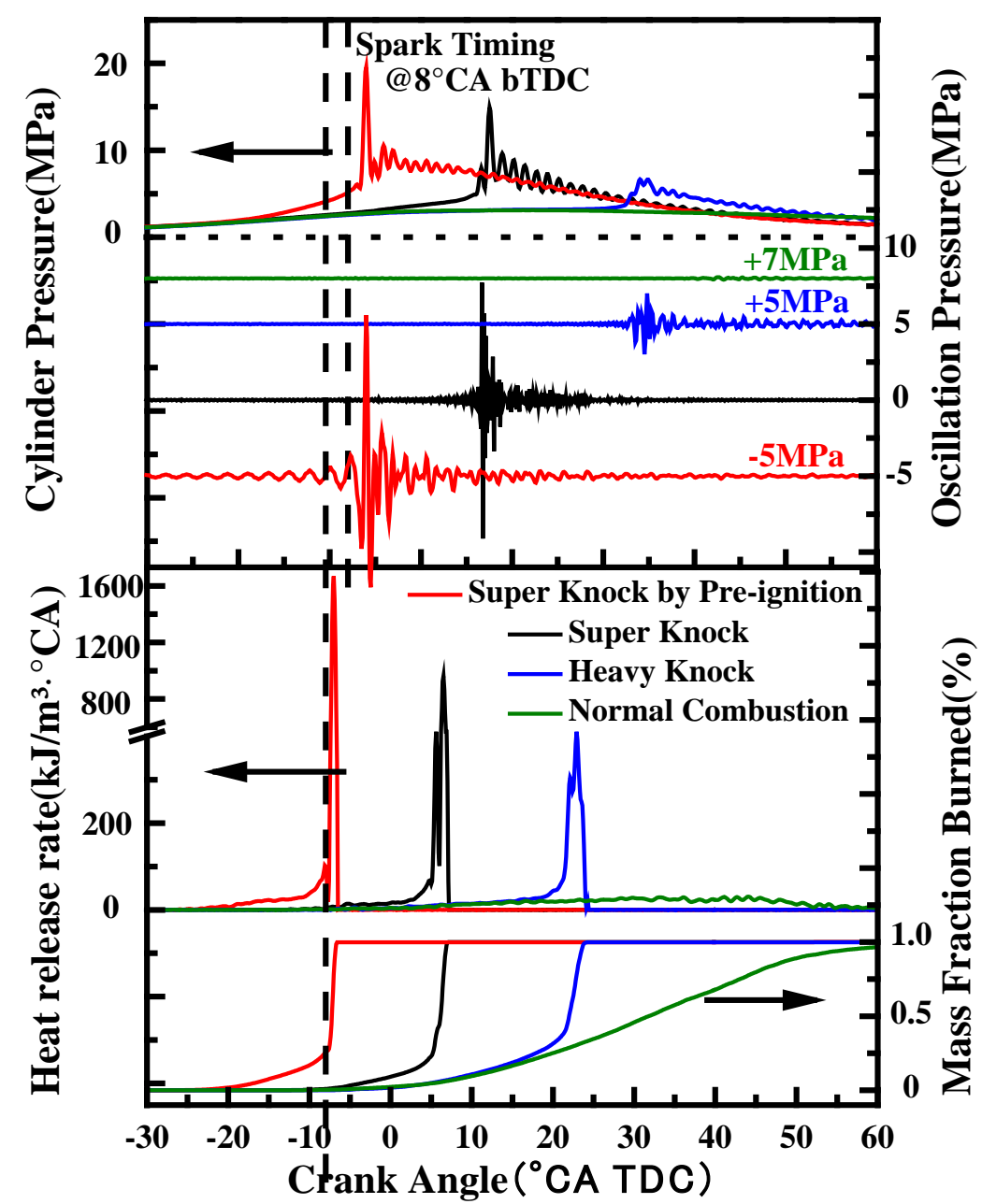

Fig. 4. Pressure profiles and heat release rates at typical knock combustions at spark timing of $8^{\circ} \mathrm{CA}$ bTDC.

Figure 4 shows in-cylinder pressure profiles, pressure oscillations (High-pass filter, $\mathrm{F}>4 \mathrm{kHz}$ ), heat release rates, and burned mass fractions over crank angle for typical cycles of normal combustion, heavy-knock, spark ignition induced super-knock, and pre-ignition induced super-knock. In this work, initial combustion duration is referred as the time from spark discharge to $10 \%$ mass fraction burned (MFB). Main combustion duration is defined as the time between $10 \%$ MFB and $90 \%$ MFB. The green lines show typical cycles of normal combustion. It can be seen from the normal combustion curve in Fig. 4 that the ignition delay time is $6.8^{\circ} \mathrm{CA}$ TDC and the main combustion duration is $39.2^{\circ} \mathrm{CA}$, respectively. But pre-ignition of mixture gas occurs due to the existence of a hot spot, resulting in the significant increase of pressure with severe pressure oscillation and heat release rates before spark ignition. In contrast, the heat release rate of super-knock induced by advanced spark ignition started after the spark timing of $8^{\circ} \mathrm{CA}$ bTDC. Figure 4 indicates a typical process of super-knock: 
214 first, strong heat release (7.4 ${ }^{\circ}$ CA bTDC) occurs; subsequently, intense pressure oscillation (6.4 ${ }^{\circ}$ CA bTDC)

215 and high peak pressure $\left(6.0^{\circ} \mathrm{CA}\right.$ bTDC) occur. It worth to mention that the ignition delay time of spark-ignition

216 induced super-knock was $13.4^{\circ} \mathrm{CA}$, but the main combustion duration was $1.3^{\circ} \mathrm{CA}$. Along with a large 217 spontaneous combustion of end-gas, strong heat release promotes the interaction between flame and pressure 218 wave, which leads to violent pressure oscillation and high peak pressure.

\subsection{Super-knock onset transition}

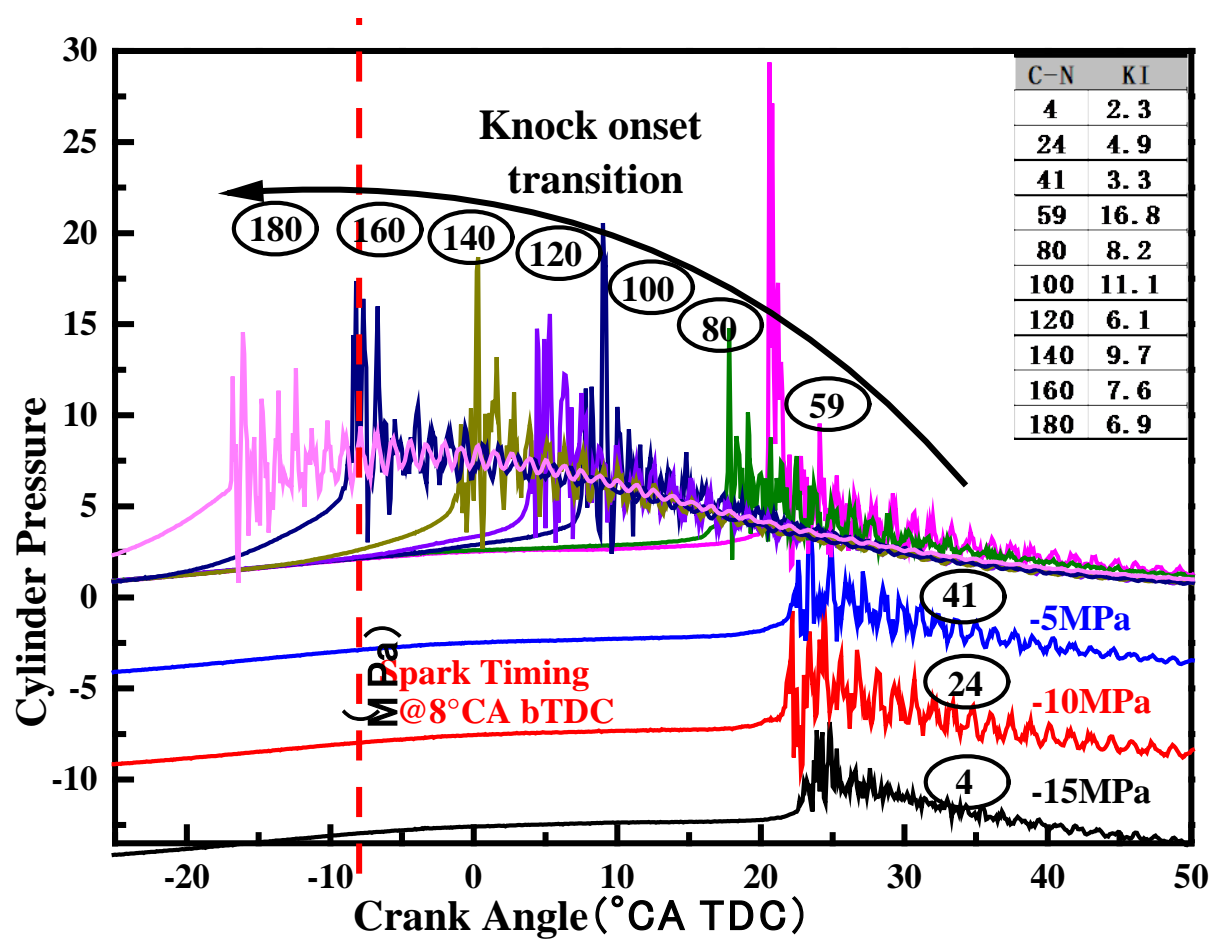

Fig. 5. Pressure profiles among different cycle numbers(C-N).

Figure 5 shows in-cylinder pressure and knock intensity (KI) of several typical super-knock cycles among 200 continuous cycles. To avoid the profile overlap, the in-cylinder pressure profiles of super-knock cycle numbers of 4, 24 and 41 were offset by $-15,-10$ and $-5 \mathrm{MPa}$, respectively. As the number of cycles increases, the start timing of the super-knock gradually advances. This advance occurs because the thermodynamic state of the end-gas enhances due to the thermodynamic state of engine as time increases. Ignition delay of the endgas is further shortened, leading to advanced auto-ignition. As a consequence, the start time of the super-knock is advanced. Figure 5 shows that the onset of pressure oscillation advances with the number of cycle (80-180). The KI values in different cycles are 8.2, 11.1, 6.1, 9.7, 7.6, and 6.9 MPa for cycle numbers are 80, 100, 120, 140,160 and 180, respectively. This data indicates the non-linear relationship between knock intensity and 
knock onset. Figure 5 also shows that super-knock can occur successively, as discussed in Fig. 2. The super-

232 knock or knock phenomena that were dominantly induced by the spark ignition were later induced by the pre-

233 ignition after several cycles. Meanwhile, the intensity of super-knock induced by the pre-ignition is not linear 234 with the increase of the pre-ignition timing. The intensity of super-knock should be determined by the heat 235 release rate of the unburned mixture. There is no direct relationship between super-knock intensity and super236 knock onset. Note that, although the present results were obtained at this situation, they also indicated that the 237 occurrence of super knock can be caused by spark ignition at a certain thermal-dynamical conditions, not only 238 pre-ignition. The detailed and very interesting pressure evolutions in 200 successive cycles are shown in Video $239 \quad$ S1 in the supplemental material.

\section{$240 \quad 3.3$ Analysis of the mechanism of super-knock}

\subsubsection{Thermal explosion theory}

Bradley et al.[31, 32] reported that the heat release rate increases exponentially with the increase of temperature, leading to extremely unstable (high pressure) auto-ignition in a high-temperature environment. The rapid release from spontaneous auto-ignition of the mixture cannot be dissipated in time, triggering the intense pressure change locally, which results in the propagation of the pressure wave outward. Therefore, according to the thermal explosion theory, whether the super-knock was caused by the pre-ignition or spark ignition is due to the spontaneous heat release of the unburned mixture auto-ignition under high temperature and pressure conditions. Consequently, the auto-ignition leads to intense pressure oscillation. In addition, the interaction between the pressure wave and the flame will also promote the auto-ignition of the mixture in the

250 flame preheating zone, which finally transfers the combustion mode from normal combustion to a detonation 251 combustion[33, 34].

The thermal auto-ignition of air-fuel mixture in the combustion chamber ahead of the propagating turbulent flame may lead to the super-knock. Essentially, engine super-knock is always combined with interactions of flame and shock wave and rapid chemical energy release. Note that, since the super-knock has continuous ultra-

high pressure and strong destructiveness, the present optical engine is used to study the normal knock combustion and cannot withstand high pressure oscillation as super-knock occurrence, especially at the present 
high compression ratio[4, 35]. Figure 6 shows the intense pressure oscillations of two different auto-ignition modes based on the fundamental experimental studies in a constant volume chamber[36, 37]. By analyzing two possible combustion modes in a constant-volume vessel, the results can explain the corresponding super-knock. The results were obtained at initial pressures of 0.4 MPa and 0.3 MPa for mode 1 and mode 2, respectively. The images were obtained by high-speed Schlieren photography. A clear density disturbance ahead of the turbulent flame (or preheated zone with high density) in the unburned gas zone was formed, especially a shock wave (Mach number about unity) produced by the turbulent flame acceleration passing through the unburned gas zone. The detailed description of turbulent flame acceleration can be found in [26]. It can be seen that auto-ignition ahead of the flame front (the brighter zone in Fig. 6 for mode 1) generated a rapid increase of in-cylinder pressure, which can rapidly consume the unburned mixture with a very fast flame tip velocity. The maximum amplitude of pressure oscillation exceeds ten times the initial pressure of spark ignition near approximately 6 MPa. For the end-gas auto-ignition (mode 2), due to the strong compression effect on the unburnt mixture of the end gas induced by the fast shock wave and temperature and pressure increase in combustion chamber, especially when the flame approaches the end gas zone, a bright quasi-detonation wave propagating rapidly with the speed of approximately $1800 \mathrm{~m} / \mathrm{s}$ was produced. At the same time, a very high pressure oscillation was generated in a split-second. This combustion mode is consistent with the previous works regarding the super knock phenomenon with deflagration to detonation obtained by Wang et al.[15] and Robert et al.[16]. Note that the end-gas auto-ignition is induced by shock wave due to the low initial temperature of $353 \mathrm{~K}$ and pressure 0.3 MPa. Overall, it may be concluded that the intense pressure oscillations with high amplitude were induced by two possible combustion mechanisms: the end-gas auto-ignition in the end-gas region of confined space, and the thermal auto-ignition of the unburned mixture in front of the propagating turbulent flame. The two possible combustion modes may have the ability to induce super-knock with a high amplitude of pressure oscillation. chemical energy release. By analyzing two possible combustion modes in a constant-volume vessel, the results can explain the corresponding super-knock. Therefore, the phenomena of producing shock in a constant-volume vessel can correspond to the mechanism of producing super-knock in SI engine. 


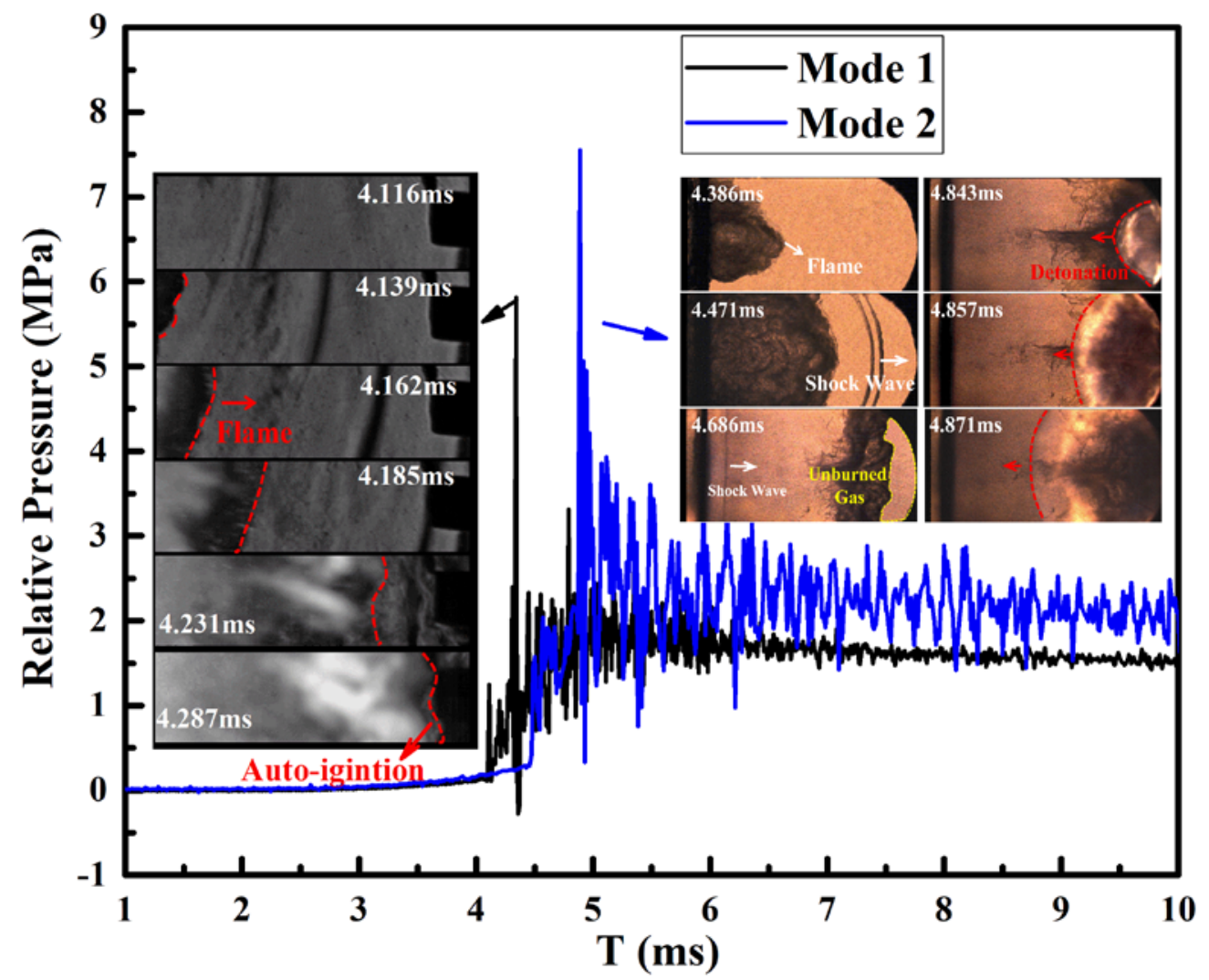

Fig. 6. Intense pressure oscillations of two different auto-ignition modes[36] (Mode 1: auto-ignition 285 ahead of flame front , and Mode 2: end-gas auto-ignition in end gas region of confined space. The red 286 line indicates the flame front due to auto-ignition). 


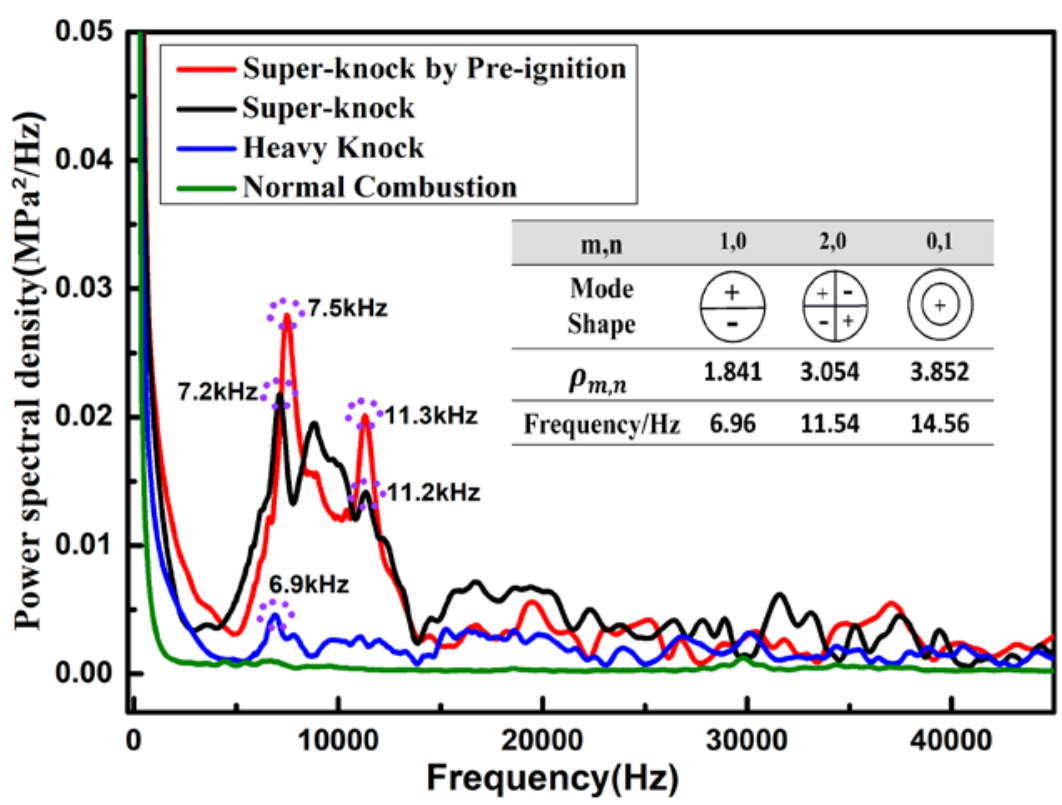

Fig. 7.FFT of in-cylinder pressure at different knock combustion modes.

The frequency characteristic of pressure oscillation is an important area of research to analyzing engine knock combustion. When knocking combustion occurs, there are intensive pressure waves and even shock waves propagating and reflecting within the cylinder, which may lead the combustion chamber to resonate based on its natural frequency. Hence, cavity resonances in engine combustion chambers further help explain the mechanism of super-knock. The cavity resonance in an engine combustion chamber depends on shape and size characteristics as well as the value of the local speed of sound. The resonance modes can be both circumferential and radial, while the axial modes are negligible since the combustion chamber height at TDC is small compared with the bore. The analytical solution of the wave equation can be used to estimating the frequencies of different resonant modes[38]. Assuming that knocking pressure wave propagates at local sound velocity, the bore and circumference of the combustion chamber is used as the characteristic lengths for calculating the radial and circumferential modes. The simplified wave equation formulation is [11]:

$$
f_{m, n}=\rho_{m, n} \frac{C}{\pi B}
$$

where $f_{m, n}$ is the knocking resonant frequency; $\rho_{m, n}$ is the corresponding resonance mode factor, $\mathrm{m}$ and $\mathrm{n}$ are the numbers of radial and circumferential pressure nodes, respectively; B is the bore of the cylinder, and c is the velocity of local sound in the combustion chamber, which depends on temperature and pressure. 
Figure 7 shows the Fast Fourier Transform (FFT) results for two typical super-knocks, the normal combustion and heavy-knock. The calculation of different resonance modes involving characteristic frequencies shows a correlation with experiments conducted by FFT. The local sound speed in the combustion chamber is estimated at $950 \mathrm{~m} / \mathrm{s}$ for gasoline-air mixture based on the temperature and pressure at TDC [38,39]. When the characteristic frequencies of the first radial mode $(1,0)$ and the second radial mode $(2,0)$ are calculated, the resonant frequencies of the different modes are $6.96 \mathrm{kHz}$ and $11.55 \mathrm{kHz}$, which is consistent with the experimental results. Therefore, the pressure wave caused by knock combustion resonated with the natural resonance frequency of the combustion chamber to enhancing the pressure wave energy, resulting in strong pressure oscillation. However, there is still high energy in the high-frequency part when super-knock occurs, which cannot be explained by acoustic theory. Therefore, it can be speculated that the pressure wave caused by super-knock may be a shock wave or detonation wave. Meanwhile, both of super-knock have the similar frequency characteristics, it can be speculated that there are some connections between super-knock and cavity resonance.

\section{Conclusions}

In this study, different knocking combustion modes were experimentally investigated using a spark ignition engine with a high compression ratio $(\mathrm{CR}=13)$. Super-knock caused by changing spark ignition was observed. Based on fundamental theory and cavity resonances, the mechanism of super-knock was discussed in this work. Different from previous studies and known knowledge [1,13], the present work gives the distinct conclusion with respect with the cause of super-knock occurrence. Based on the experimental results, several key conclusions are summarized as follows:

Super-knock occurrence does not only originate from pre-ignition, but also advancing the spark timing can also induce the super-knock while very high pressure oscillations and a high compression ratio. The high compression ratio $(\mathrm{CR}=13)$ could generate sufficiently high thermal-dynamic conditions, which is the root cause. As long as the pressure and temperature at top dead center are high enough (regardless of pre-ignition and spark ignition), they have the possibility to become super-knock. Meanwhile, the intensity of super-knock induced by the pre-ignition does not have a linear relationship with increasing the pre-ignition timing, which should be 
determined by the heat release rate of the mixture. There is no relationship between super-knock intensity and

333 super-knock onset. The super-knock occurrence is not stochastic, and it can occur successively, which was

334 observed in the present experiment. Furthermore, when researching the repeated occurrences of super-knock,

335 the super-knock induced by spark timing was gradually evolved to being induced by pre-ignition.

\section{$336 \quad$ Nomenclature}

\begin{tabular}{ll}
\hline bTDC & after top dead center \\
bTDC & before top dead center \\
DI & direct injection \\
SI & spark ignition \\
CAD & crank angle degree \\
TDC & top dead center \\
KI & knock intensity \\
FFT & Fast Fourier transform \\
C-N & cycle numbers \\
RON & research octane number \\
WOT & wide-open throttle \\
\hline
\end{tabular}

$338 \quad$ List of Supplemental Material

339 Video 1- Detailed pressure evolutions in 200 successive cycles.mp4

\section{Acknowledgments}

This study is supported by the National Natural Science Foundation of China (Grant No. 91641203, 91741119,

34251476114

\section{References}

345 [1] Wang Z, Liu H, Reitz RD. Knocking combustion in spark-ignition engines. Prog Energy Combust Sci. $346 \quad 2017 ; 61: 78-112$.

347 [2] Kalghatgi GT, Bradley D. Pre-ignition and 'super-knock' in turbo-charged spark-ignition engines. 348 International Journal of Engine Research. 2012;13(4):399-414.

349 [3] Wang S, Zhao F, Liu Z, Hao H. Impacts of a super credit policy on electric vehicle penetration and 350 compliance with China's Corporate Average Fuel Consumption regulation. Energy. 2018;155:746-62.

351 [4] Catapano F, Sementa P, Vaglieco BM. Characterization of Knock Tendency and Onset in a GDI Engine by 352 Means of Conventional Measurements and a Non-Conventional Flame Dynamics Optical Analysis. SAE Int J 
Engines. 2017;10:2439-50.

[5] Liu C, Song H, Zhang P, Wang Z, Wooldridge MS, He X, et al. A rapid compression machine study of autoignition, spark-ignition and flame propagation characteristics of $\mathrm{H} 2 / \mathrm{CH} 4 / \mathrm{CO} /$ air mixtures. Combust Flame. 2018;188:150-61.

[6] Zhou L, Gao D, Zhao J, Wei H, Zhang X, Xu Z, et al. Turbulent flame propagation with pressure oscillation in the end gas region of confined combustion chamber equipped with different perforated plates. Combust Flame. 2018;191:453-67.

[7] Wei H, Shao A, Hua J, Zhou L, Feng D. Effects of applying a Miller cycle with split injection on engine performance and knock resistance in a downsized gasoline engine. Fuel. 2018;214:98-107.

[8] Wei H, Zhu T, Shu G, Tan L, Wang Y. Gasoline engine exhaust gas recirculation - A review. Appl Energy. 2012;99:534-44.

[9] Catapano F, Sementa P, Vaglieco BM. Air-fuel mixing and combustion behavior of gasoline-ethanol blends in a GDI wall-guided turbocharged multi-cylinder optical engine. Renewable Energy. 2016;96:319-32.

[10] Marseglia G, Costa M, Catapano F, Sementa P, Vaglieco BM. Study about the link between injection strategy and knock onset in an optically accessible multi-cylinder GDI engine. Energy Convers Manage. 2017;134:1-19.

[11] Michael G, Marc S. Knocking in Gasoline Engines . 5th International Conference, December 12-13, 2017, Berlin, Germany.

[12] Wang Z, Liu H, Song T, Qi Y, He X, Shuai S, et al. Relationship between super-knock and pre-ignition. International Journal of Engine Research. 2015;16(2):166-80.

[13] Kalghatgi G. Knock onset, knock intensity, superknock and preignition in spark ignition engines. Int J Engine Res. 2018;19(1):7-20.

[14] Xu H, Yao A, Yao C, Gao J. Proper orthogonal decomposition for energy convergence of shock waves under severe knock. Energy. 2017;128:813-29.

[15] Qi Y, Wang Z, Wang J, He X. Effects of thermodynamic conditions on the end gas combustion mode associated with engine knock. Combust Flame. 2015;162(11):4119-28.

[16] Robert A, Richard S, Colin O, Poinsot T. LES study of deflagration to detonation mechanisms in a downsized spark ignition engine. Combustion and Flame. 2015;162(7):2788-807.

[17] Bates L, Bradley D, Paczko G, Peters N. Engine Hot Spots: Modes of Auto-ignition and Reaction Propagation. Combustion and Flame. 2016;166:80-5.

[18] Wei H, Gao D, Zhou L, Pan J, Tao K, Pei Z. Experimental observations of turbulent flame propagation effected by flame acceleration in the end gas of closed combustion chamber. Fuel. 2016;180:157-63.

[19] Gu X, Emerson D, Bradley D. Modes of reaction front propagation from hot spots. Combustion and flame. 2003;133(1):63-74.

[20] Kalghatgi G, Algunaibet I, Morganti K. On Knock Intensity and Superknock in SI Engines. SAE Int J Engines. 2017;10(3):1051-63.

[21] Rudloff J, Zaccardi JM, Richard S, Anderlohr JM. Analysis of pre-ignition in highly charged SI engines: Emphasis on the auto-ignition mode. Proc Combust Inst. 2013;34(2):2959-67.

[22] Dahnz C, Han K-M, Spicher U, Magar M, Schießl R, Maas U. Investigations on pre-ignition in highly supercharged SI engines. SAE Int J Engines. 2010;3:214-24.

[23] Wang Z, Qi Y, He X, Wang J, Shuai S, Law CK. Analysis of pre-ignition to super-knock: Hotspot-induced deflagration to detonation. Fuel. 2015;144:222-7.

[24] Brecq G, Bellettre J, Tazerout M. A new indicator for knock detection in gas SI engines. International Journal of Thermal Sciences. 2003;42(5):523-32. 
399 [26] Sheppard CGW, Tolegano S, Woolley R. On the Nature of Autoignition Leading to Knock in HCCI Engines. 400 SAE Technical Papers. 2002;1:2831.

401 [27] Wei H, Hua J, Pan M, Feng D, Zhou L, Pan J. Experimental investigation on knocking combustion 402 characteristics of gasoline compression ignition engine. Energy. 2018;143:624-33.

403 [28] Liu Y, Shi X, Deng J, Chen Y, Hu M, Li L. Experimental Study on the Characteristics of Knock under DI404 HCCI Combustion Mode with Ethanol/Gasoline Mixed Fuel. SAE Technical Papers. 2013;1:0544.

405 [29] Amann M, Mehta D, Alger T. Engine Operating Condition and Gasoline Fuel Composition Effects on Low406 Speed Pre-Ignition in High-Performance Spark Ignited Gasoline Engines. SAE Int J Engines. 2011;4(1):27440785.

408 [30] Zahdeh A, Rothenberger P, Nguyen W, Anbarasu M, Schmuck-Soldan S, Schaefer J, et al. Fundamental 409 Approach to Investigate Pre-Ignition in Boosted SI Engines. SAE Int J Engines. 2011;4(1):246-73.

410 [31] Bradley D, Kalghatgi GT, Golombok M, Yeo J. Heat release rates due to autoignition, and their relationship 411 to knock intensity in spark ignition engines. Symposium on Combustion. 1996;26(2):2653-60.

412 [32] Bates L, Bradley D. Deflagrative, auto-ignitive, and detonative propagation regimes in engines. Combust 413 Flame. 2017;175:118-22.

414 [33] Wei H, Gao D, Zhou L, Feng D, Chen R. Different combustion modes caused by flame-shock interactions 415 in a confined chamber with a perforated plate. Combust Flame. 2017;178:277-85.

416 [34] Wei H, Chen C, Shu G, Liang X, Zhou L. Pressure wave evolution during two hotspots autoignition within 417 end-gas region under internal combustion engine-relevant conditions. Combust Flame. 2018;189:142-54.

418 [35] Feng D, Buresheid K, Zhao H, Wei H, Chen C. Investigation of lubricant induced pre-ignition and knocking 419 combustion in an optical spark ignition engine. Proc Combust Inst. 2018.

420 [36] Zhou L, Zhong L, Zhao J, Gao D, Wei H. Flame propagation and combustion modes in end-gas region of 421 confined space. Combust Flame. 2018;190:216-23.

422 [37] Wei H, Gao D, Zhou L, Zhao J, Chen R. Experimental Investigation of Turbulent Flame Propagation and 423 Pressure Oscillation in a Constant Volume Chamber Equipped With an Orifice Plate. Combust Sci Technol. 424 2017:1-17.

425 [38] Galloni E. Dynamic knock detection and quantification in a spark ignition engine by means of a pressure 426 based method. Energy Convers Manage. 2012;64(12):256-62.

427 [39] Wei H, Feng D, Pan M, Pan J, Rao X, Gao D. Experimental investigation on the knocking combustion 428 characteristics of n-butanol gasoline blends in a DISI engine. Appl Energy. 2016;175:346-55. 